\title{
Galvanic vestibular stimulation produces sensations of rotation consistent with activation of semicircular canal afferents
}

\section{Raymond Francis Reynolds* and Callum J. Osler}

School of Sport and Exercise Sciences, College of Life and Environmental Sciences, University of Birmingham, Birmingham, UK

*Correspondence: r.f.reynolds@bham.ac.uk

Edited by:

Miriam Welgampola, University of Sydney, Australia

Reviewed by:

Omar Mian, University College London, UK

Galvanic Vestibular Stimulation (GVS) is a simple method for evoking sensations of movement (Fitzpatrick and Day, 2004). It involves passing small currents, typically $<5 \mathrm{~mA}$, across the mastoid processes. A recent article by Cohen et al. (2012) discussed the mechanism of action of GVS. The authors concluded that although GVS excites both otolith and semicircular canal afferents, only otolith-related behavioral responses are induced. Specifically, it was stated that human subjects "... do not experience sensations of rotation and do not display ocular nystagmus, which would occur if the semicircular canals were continuously stimulated." However, a growing body of evidence from perceptual, oculomotor, and whole-body experiments confirms that GVS does indeed produce sensations of rotation consistent with canal stimulation.

Fitzpatrick et al. (2002) investigated the effect of binaural bipolar GVS upon the ability of supine subjects to report rotation around a vertical axis. When stimulation was applied concurrently with real rotation, subjects reported lesser, or greater movement depending on stimulus polarity. To minimize activation of the otoliths, the axis of (real) rotation was collinear with the midline between the ears. However, even when this axis was altered to produce a combination of translation and rotation, it did not change the effect of GVS upon perception. This suggests that GVS primarily influences the sensation of rotation, not translation. In a similar experiment, Day and Fitzpatrick (2005) determined the precise axis of this "virtual" rotation vector. Seated subjects adopted different head pitches while being spun on a rotary chair. Again, when GVS was applied, sensations of rotation could be increased or decreased in a polarity-dependent fashion. Maximal effects occurred when the naso-occipital axis was approximately co-linear with the axis of real rotation (i.e., with the head pitched fully up or down). With the head close to the neutral position, such that Reid's plane was tilted $18.8^{\circ}$ above horizontal (i.e., slight nose-up tilt), the effect of GVS upon rotation sensation was zero. This suggests that GVS evokes a sensation of head roll around a naso-occipital axis. Using a modeling approach, the authors elegantly demonstrated that this axis is a direct consequence of the anatomical orientation of the canals (Blanks et al., 1975). Based on the assumption that GVS modulates all vestibular afferents equally (Goldberg et al., 1984), they calculated the theoretical axis of head rotation when equal signals from all six canals are combined. It transpires that the resulting axis is naso-occipital, and elevated $16.4^{\circ}$ relative to Reid's plane. This tallies remarkably well with the data gained from the chair rotation experiment.

Evoked eye movements corroborate these data. Many studies have described a torsional eye movement response to GVS (Schneider et al., 2000, 2002; Jahn et al., 2003; MacDougall et al., 2005). This consists not only of a fixed offset of eye position as one might expect from pure otolith activation, but contains alternating fast and slow phases, consistent with a canal-evoked nystagmus caused by head roll. Schneider et al. (2002) compared the ocular response to GVS with that caused by head roll. They found that GVS produced essentially the same eye movement as pure head rotation; i.e., torsional offset accompanied by nystagmus. This raises the possibility that both characteristics of the GVS-evoked eye movement can be explained entirely on the basis of rotation.

Galvanic Vestibular Stimulation-evoked body movements agree with the perception and eye movement data. With the head tilted up or down GVS evokes locomotor turning (Fitzpatrick et al., 2006), and in standing subjects it induces vertical torque reactions (Reynolds, 2011). In the absence of somatosensory information GVS evokes a continuous body tilt response for the duration of the stimulus, rather than merely a fixed offset of body position (Day and Cole, 2002). Furthermore, prolonged stimuli evoke oscillating "nodding" lateral head responses, akin to ocular nystagmus (Wardman et al., 2003). These movements are consistent with a counteractive response to a sensation of continuous rotation, and cannot be readily attributed to sensations of tilt or linear acceleration. Nevertheless, the possibility of an otolith-based response has not been definitively excluded. Cathers et al. (2005) examined the effect of head pitch on GVS-evoked balance responses. Robust sway responses were observed with the head upright, but with the head tilted down the main balance response was abolished, leaving only a small transient sway. This transient response can be explained as a reaction to a sense of inter-aural linear acceleration, suggesting it can be attributed to otolith stimulation. However, a recent study examining the effect of head orientation on this response suggests it is not compatible with the anatomical properties of the otolith organs (Mian et al., 2010). This raises the possibility that weak trans-mastoidal current may also stimulate non-vestibular pathways to generate motor output. But regardless of the origin of the early transient response, it is dwarfed in magnitude by the later rotation-based movement consistent with canal stimulation.

In summary, overwhelming evidence from perception, anatomy, modeling, oculomotor, and whole-body responses all converges toward the same conclusion: GVS is primarily interpreted by the brain 
as head roll, consistent with activation of semicircular canal afferents. Whether it also evokes sensations of tilt and/or linear acceleration, which would be indicative of otolith activation, is less certain (for a more comprehensive recent review, see St George and Fitzpatrick, 2011).

\section{REFERENCES}

Blanks, R. H., Curthoys, I. S., and Markham, C. H. (1975). Planar relationships of the semicircular canals in man. Acta Otolaryngol. 80, 185-196.

Cathers, I., Day, B. L., and Fitzpatrick, R. C. (2005). Otolith and canal reflexes in human standing. J. Physiol. (Lond.) 563, 229-234.

Cohen, B., Yakushin, S. B., and Holstein, G. R. (2012). What does galvanic vestibular stimulation actually activate? Front. Neurol. 2:90. doi: 10.3389/ fneur.2011.00090

Day, B. L., and Cole, J. (2002). Vestibular-evoked postural responses in the absence of somatosensory information. Brain 125, 2081-2088.

Day, B.L., and Fitzpatrick, R.C. (2005).Virtual head rotation reveals a process of route reconstruction from human vestibular signals. J. Physiol. (Lond.) 567, 591-597.

Fitzpatrick, R. C., Butler, J. E., and Day, B. L. (2006). Resolving head rotation for human bipedalism. Curr. Biol. 16, 1509-1514.
Fitzpatrick, R. C., and Day, B. L. (2004). Probing the human vestibular system with galvanic stimulation. J. Appl. Physiol. 96, 2301-2316.

Fitzpatrick, R. C., Marsden, J., Lord, S. R., and Day, B. L. (2002). Galvanic vestibular stimulation evokes sensations of body rotation. Neuroreport 13, 2379-2383.

Goldberg, J. M., Smith, C. E., and Fernandez, C. (1984). Relation between discharge regularity and responses to externally applied galvanic currents in vestibular nerve afferents of the squirrel monkey. J. Neurophysiol. 51, 1236-1256.

Jahn, K., Naessl, A., Schneider, E., Strupp, M., Brandt, T., and Dieterich, M. (2003). Inverse U-shaped curve for age dependency of torsional eye movement responses to galvanic vestibular stimulation. Brain 126, 1579-1589.

MacDougall, H. G., Brizuela, A. E., Burgess, A. M., Curthoys, I. S., and Halmagyi, G. M. (2005). Patient and normal three-dimensional eyemovement responses to maintained (DC) surface galvanic vestibular stimulation. Otol. Neurotol. 26, 500-511.

Mian, O. S., Dakin, C. J., Blouin, J. S., Fitzpatrick, R. C., and Day, B. L. (2010). Lack of otolith involvement in balance responses evoked by mastoid electrical stimulation. J. Physiol. (Lond.) 588, 4441-4451.

Reynolds, R. F. (2011). Vertical torque responses to vestibular stimulation in standing humans. J. Physiol. (Lond.) 589, 3943-3953.
Schneider, E., Glasauer, S., and Dieterich, M. (2000). Central processing of human ocular torsion analyzed by galvanic vestibular stimulation. Neuroreport 11 , 1559-1563.

Schneider, E., Glasauer, S., and Dieterich, M. (2002). Comparison of human ocular torsion patterns during natural and galvanic vestibular stimulation. $J$. Neurophysiol. 87, 2064-2073.

St George, R. J., and Fitzpatrick, R. C. (2011). The sense of self-motion, orientation and balance explored by vestibular stimulation. J. Physiol. (Lond.) 589, 807-813.

Wardman, D. L., Day, B. L., and Fitzpatrick, R. C. (2003). Position and velocity responses to galvanic vestibular stimulation in human subjects during standing. J. Physiol. (Lond.) 547, 293-299.

Received: 07 May 2012; accepted: 11 June 2012; published online: 28 June 2012.

Citation: Reynolds RF and Osler CJ (2012) Galvanic vestibular stimulation produces sensations of rotation consistent with activation of semicircular canal afferents. Front. Neur. 3:104. doi: 10.3389/fneur.2012.00104

This article was submitted to Frontiers in Neuro-otology, a specialty of Frontiers in Neurology.

Copyright $\odot 2012$ Reynolds and Osler. This is an openaccess article distributed under the terms of the Creative Commons Attribution Non Commercial License, which permits non-commercial use, distribution, and reproduction in other forums, provided the original authors and source are credited. 